\title{
Post-Traumatic Stress Disorder And Coping Among Career Professional Firefighters
}

Rudy Nydegger, Ph.D., ABPP, Union College, USA

Liesl Nydegger, MPH, Claremont Graduate University, USA

Frank Basile, BA, Former Student, Union College, USA

\begin{abstract}
This study explores the relationship between years of service for professional firefighters and the prevalence of post-traumatic stress disorder (PTSD). Further, the study examines the specific coping mechanisms that the firefighters use to deal with the stress of their jobs. In order to assess the presence of PTSD symptoms, the Post-Traumatic Stress Disorder Checklist-Civilian Version $(P C L-C V)$ was employed, and the Brief COPE Survey was also used to assess the different types of coping strategies that were reported by firefighters. The subjects were 91 paid, career firefighters from two different communities in Upstate New York. Results clearly showed that firefighters who have more years of service also demonstrated a higher frequency of symptoms suggestive of PTSD. Further, results of the Brief COPE survey demonstrated that firefighters who have more years on the job tend to utilize more negative and inefficient coping approaches. The implications of these results and suggestions for helping fire departments deal with these issues are discussed.
\end{abstract}

Keywords: post-traumatic stress syndrome; firefighters; PTSD coping strategies

\section{INTRODUCTION}

$\mathrm{n}$ recent years, considerable attention has been paid to the impact of stress in the workplace and the personal and organizational costs of this stress. Stress refers to the psychological and physical responses that characterize a person's adaptive reaction to changes in their environment. Stress itself is neutral, but when the conditions or stimuli that produce stress (stressors) result in outcomes that have an adverse impact, it becomes an issue that may need to be addressed. Excessive stress will produce psychological and physical problems that may negatively affect a person's health and functioning and often results in outcomes that adversely impact their jobs including: increased medical and mental health costs, lost work time, decreased efficiency, lower productivity, higher turnover, and decreased job satisfaction. Some of the primary sources of work stress include: the employees feeling that they have no control over their job and work; high demands, including unrealistic workloads and challenging time pressures; lack of job security; understaffing; mandatory overtime; and violence and harassment (NYSPEF, 2006).

Firefighters are a group of professionals who frequently are exposed to high stress situations that can present challenges to their ability to cope with their jobs. Some of the main sources of stress firefighters face on a daily basis include responding to routine emergencies which are coupled with traumatic and emotionally difficult incidents that can occur at any time (Del Ben, et al., 2006). They will regularly deal with intense traumatic events such as gruesome injuries or death and unpredictable and dangerous situations (Heinrichs, et al., 2005). While most of the events that firefighters face are relatively benign and simple, they never know when something dramatic or tragic may occur. Further, Haslam \& Mallon (2003) demonstrated that small-scale incidents like traffic accidents were no different than larger scale events in terms of the stress impact. This suggests that the cumulative impact of minor events may be more important that it may appear to be on the surface, and this might lead to people minimizing situations that might become more problematic over time. 
It is also apparent that different types of stressful situations will have different impacts on firefighters. For example, situations involving children were perceived as being more stressful than those dealing with adults, often leading to more troublesome symptoms like intrusive memories (Haslam \& Mallon, 2003). Other kinds of stressors that Haslam \& Mallon (2003) found to be stressful for firefighters included managerial and organizational problems, shift work, and time constraints. Sometimes firefighters may have feelings of guilt and distress after working at the scene of a mass casualty incident (MCI) because they were not able to save as many victims as they wanted to (Beaton, et al., 1999). Even performing routine tasks such as cardiopulmonary resuscitation (CPR) on patients has also been linked to psychological distress in firefighters (Beaton, et al., 1998). Research also suggests that the extent of the traumatic event is related to how severe and chronic the psychological distress is (Brown, et al., 2002).

PTSD is commonly found in combat veterans, rape/assault victims, robbery victims, and emergency service workers (e.g., firefighters, police officers, emergency medical technicians) (Barlow \& Durand, 2005). In terms of prevalence, PTSD has a lifetime rate of $8 \%$ which means that over an entire lifespan, $8 \%$ of people will develop PTSD at one time or another (Kessler, et al., 1995), but in American firefighters the lifetime prevalence rate is 22.2\% (Heinrichs, et al., 2005). Clearly, firefighters are almost three times at greater risk of developing PTSD than people in the general population. It is tempting to look at single events as producing PTSD, but in professionals like firefighters it may be more likely to be the cumulative impact of multiple traumas over time that lead to the development of PTSD (Del Ben, et al., 2006). Corneil (1995) conducted a study on traumatic stress in firefighters, and this study sampled professional, urban firefighters from Canada, and found a positive relationship between the number of years on the job and PTSD scores on a self-report inventory. This suggests very strongly that the longer a professional firefighter has been on the job, the greater the likelihood that they will experience PTSD symptoms.

PTSD has a complex and troubling set of symptoms that can create significant difficulties for the people who suffer from this disorder. Generally, we look at three types of symptoms with PTSD:

1. Hyperarousal

a. Irritability

b. Increased startle reaction

c. Hypervigilance

d. Sleep difficulties

2. Re-experiencing or intrusion

a. $\quad$ Vivid memories

b. Nightmares

c. Re-experiencing the event

d. Anything that reminds them of the trauma is troubling

3. Avoidance and emotional numbing

a. Avoidance of feelings, thoughts, persons, places, situations that evoke the memories

b. Loss of interest in usual activities

c. Feeling estranged from others and even from their own feelings (American Psychiatric Association, 2000)

There is a common theme in these difficulties--fixation on the trauma and this can pervade many, if not most, areas of a person's life. There are differences in people with respect to the propensity that they may have to develop PTSD when exposed to traumatic events, and some people are more likely to develop this disorder than others. For example, preexisting high levels of hostility and low levels of self-efficacy make people more likely to experience symptoms of PTSD following a traumatic event. Firefighters who had high levels of hostility and low levels of self-efficacy at baseline had steady increases in scores measuring PTSD symptoms over the two years in the studies. These subjects showed higher levels of depression, anxiety, general psychological morbidity, global severity of symptoms, and had difficulty recognizing and expressing their emotions. Conversely, firefighters with low levels of hostility and/or high levels of self-efficacy had no increase in psychopathological symptoms over the two-year period of the study (Heinrichs, et al., 2005). 
There are other factors that also predict susceptibility to PTSD including job-related traumatic events, previous psychological treatment, the age at which firefighters began working, and the experience of horror as a result of the trauma, all predicted PTSD symptoms (Del Ben, et al., 2005). In addition, hypersensitivity to smells (viz., burnt flesh) (Haslam \& Mallon, 2003), was also linked to higher incidence of PTSD. It was also demonstrated that people with an external locus of control were more prone experience psychological distress in a traumatic situations (Brown, et al., 2002). There are also some positive findings that suggest that firefighters who are low in attachment anxiety and avoidance experience higher levels of psychological well-being (Landen \& Wang, 2010), and are therefore less likely to experience PTSD when faced with a traumatic situation.

Coping with trauma is a difficult challenge for anyone, and how effectively a person copes with trauma is very important in determining the quality of their adjustment following a traumatic event. Each person will cope with trauma in a unique and individual way, and sometimes the coping strategies will produce additional problems. Positive coping strategies are those that will help the person recover from the trauma and to improve their level of functioning and include such things as turning to spiritual supports, actively pursuing social support, acceptance of the events and the trauma, and humor. Other coping strategies are considered to be "negative" because they tend to make the situation more difficult or present new problems to deal with. For example, some negative strategies would include self-blame, denial, and substance abuse, and while these too are adaptive in the sense that they may relieve some of the symptoms temporarily, it is likely that they will actually make the situation worse for the victim, and can lead to more serious problems in the future (Carver, et al., 1989). The strategies that may be used to cope with stress and/or trauma will differ between individuals and also between different professions, but it is also expected that years of service will also have some impact on the number and types of coping strategies that are used.

There are a variety of studies that have examined the effects of different types of coping mechanisms as they impact the firefighters who experience stress and trauma on the job. It has been demonstrated that PTSD recovery is positively affected by having good social support systems, and conversely, if the patients have high levels of hostility, one result of this is to have either decreased or absent social support systems (Heinrichs, et al., 2005. Further, having good social support systems leads to higher levels of self-efficacy in patients or victims of trauma, and this will positively impact how they respond to trauma and take responsibility for their own recovery therefore responding better to treatment or support (Heinrichs, et al., 2005). The type and severity of trauma will not only impact coping, but it has also been found that different types of coping strategies work better with different levels of trauma. For example, for low-level trauma exposure, emotion-focused coping was associated with less psychological distress (Brown, et al., 2002). This means that following a lower level trauma, people did better when they focused on managing their own reactions to the situation. However, following high-level trauma exposure, more task-focused coping was better for reducing psychological distress (Brown, et al., 2002). Thus, following a more severe trauma people seemed to do better when they focused on doing things differently to cope rather than just focusing on their emotions and thoughts. There is another psychological variable called "locus of control" that is related to coping with trauma as well. People with internal locus of control largely feel in control of things that happen to them, and people with external locus of control usually feel that their outcomes are largely dependent of factors outside of themselves (e.g., fate, other people, etc.). It was discovered that people with external locus of control were more likely to engage in avoidance coping mechanisms which can lead to more psychological distress for the victims (Brown, et al., 2002).

It was demonstrated that firefighters, with high levels of resources to support them, perceived their work environment as less stressful, and manifested fewer mental health problems such as somatic complaints, anxiety, insomnia, and depression (Oginska-Bulik, 2005). Conversely, members of firefighting units with less adequate supports were more vulnerable to distress and distress-related sequelae, such as drinking alcohol to cope, which is mediated by distress (Bacharach, et al., 2008). This means is that when firefighters do not have good support systems they are more likely to experience distress and are more likely to turn to alcohol as a means of coping with the distress. Further, firefighters with more secure attachment functioning typically engage in more adaptive and healthier coping strategies while those who scored high in attachment avoidance and/or anxiety tend to employ less adaptive coping strategies (Landen \& Wang, 2010).

In terms of coping, it has been suggested that firefighters would benefit from coping skills training with a focus on anger management, emotional disclosure, attribution training, and relaxation training (Brown, et al., 2002). 
The research literature regarding the importance of interventions to prevent or treat reactions to trauma generally supports the notion that support is helpful. One study looked at the availability of support and the effects of different types of support for firefighters following trauma, and they demonstrated that no intervention was generally viewed unfavorably by firefighters, and the presence of support was seen as being positive. Even something as simple as informal discussions was perceived as very beneficial, and most firefighters support the idea that a strong, supportive institutional culture is important when coping with the effects of trauma (Jeanette \& Scorbia, 2008). Others have found that social support predicts who will experience problems following a traumatic event, and that humor is a good way to increase social support and to relieve stress (Haslam \& Mallon, 2003). Currently, support services are not always seen as socially acceptable due to the "macho image" of firefighting, although it has been found that debriefing following a difficult situation was helpful to firefighters, but it was not more helpful than simply talking to colleagues about the difficult situation (Haslam \& Mallon, 2003).

The present study was designed to determine the relationship between stress and PTSD in professional career firefighters, and to look at the types of coping strategies that firefighters use to cope with the work stress that they experience. The following hypotheses were offered and tested:

1. Hypothesis 1: It was predicted that there will be a significant relationship between the years experienced as a firefighter and the experience of symptoms of PTSD.

2. Hypothesis 2: It was predicted that the longer a firefighter has been on the job, the greater the likelihood that they will employ positive means of coping with stress.

3. Hypothesis 3: It was predicted that the most commonly used coping strategies will be three positive coping mechanisms (humor, acceptance, and religion), and one negative strategy (substance use).

\section{METHOD}

\section{Participants}

Ninety-one male paid professional firefighters from two urban fire departments in upstate NY participated in this study. The mean number of years working in the fire service was 14.66 for this sample with a maximum of 35 years and a minimum of six months. The mean age of the firefighters was 40.32 with a maximum of 60 years old and a minimum of 22 .

\section{Procedure}

The Chiefs from each of the fire departments were contacted individually, and the research, its purpose, and the procedures were explained and discussed. The importance of confidentiality and privacy were emphasized and questions were asked and answered. The Chiefs were also told that participation in the study would be entirely voluntary and anonymous and that no firefighter should be included in the study if they preferred not to be a subject. After questions were asked and answered, permission to conduct the study was granted and the survey packets and instructions were given to the Chiefs. During training each day at work, the Chief would distribute the survey packets and explain the study. There were no incentives provided for participation, and each firefighter who was part of the study was a volunteer. The departments were given 30 days to complete the surveys and to collect them, and this was done to make sure that each member of the Department had an opportunity to complete the survey if they chose to do so. Following this time period the packets were picked up from the Departments and the data were analyzed.

The surveys were given to the Chiefs in boxes which contained 100 packets of materials. Each packet contained a letter of explanation and directions, a consent form to sign and an additional copy that the subjects could keep for themselves, seven pages of survey questions (divided into three parts), and one page with debriefing information. The title page provided an explanation of the study and instructions regarding the surveys and information about voluntary participation and confidentiality. The participants were told explicitly that they could choose to participate or not and that there would be no consequences for not participating since they would turn in the packets sealed, and if they chose not to respond, no one would know whose packet it was, and only the researchers would see the opened packets. They were also told that they could decide to withdraw from the study at 
any time. The signed consent form was to be put into a sealed envelope and submitted separately from the rest of the packet. When the surveys were completed (or not) they were put into a sealed manila envelope and put back into the box and collected by the Chief to be returned to the experimenters.

The survey was divided into three sections with the first part consisting of demographic information such as sex, age, years in the fire department, and other relevant information. Part 2 consisted of the Post-Traumatic Stress Disorder Checklist - Civilian Version (PCL-CV) which is a seventeen-item self-report measure of PTSD symptoms which corresponds to the diagnostic criteria in the DSM-IV (American Psychiatric Association, 2000). Participants were informed that each question listed problems and complaints (symptoms) that people may experience in response to traumatic events at work. They were instructed to think about the past year and to remember a traumatic event that happened at work, and were then asked to indicate how much they have been affected by each problem or complaint in the past month. They then rated each symptom they experienced on a five-point Likert scale ranging from 1 (not at all) to 5 (extremely); a score of 50 or above is indicative of a person having PTSD.

Part 3 of the survey packet contained a questionnaire called the Brief COPE which is a 28 item self report inventory consisting of 14 categories that assess a broad range of coping categories and responses identified by each participant. The 14 categories included: self-distraction; active coping; denial; substance use; use of emotional support; use of instrumental support; behavioral disengagement; venting; positive reframing; planning; humor; acceptance; religion; and self blame. Subjects were instructed to rate each statement on the basis of how often they participated in the identified activity during the past month, that was in response to a traumatic event that had occurred in the past year. Participants rated their coping responses in terms of frequency during the past month on a five-point Likert scale ranging from 1 (I haven't been doing this at all) to 5 (I've been doing this a lot). Since these are independent measures, there is not an aggregate score from this questionnaire, but rather a relative frequency of responding to each of the different coping approaches. These coping styles were grouped into two categories: positive coping styles (including active coping, use of emotional support, positive reframing, planning, humor, acceptance, and religion); and, negative coping styles (including self-distraction, denial, substance use, use of instrument support, behavioral disengagement, venting, and self-blame). The categories of positive and negative coping styles were based on the expected outcomes of the specific behaviors with positive improving the situation or reducing the negative impact of the traumatic/stressful event, and the negative coping styles expected to produce outcomes that did not improve the situation or did not lessen the negative impact of the traumatic/stressful event on the subject.

\section{RESULTS}

As hypothesized, there was a significant positive correlation between number of years working as a firefighter and the presence of self-reported PTSD symptoms ( $r=.224, \mathrm{p}<.05)$. The mean PTSD score on the PCL$\mathrm{CV}$ was 27.26 with a maximum score of 70 . Any score over 50 strongly suggests that the person presents enough symptoms of PTSD to be diagnosed with that condition. In the present sample, there were six participants (6.6\%) who scored 50 or higher, and who would probably be diagnosed with PTSD. In terms of the symptoms that were expressed, Table 1 has the mean score and rank of each symptom:

In contrast with the hypotheses in this study, it was demonstrated that years of service as a firefighter was not related to the use of more "positive" forms of coping. In fact, in all seven of the positive coping categories there was not one significant correlation between years of service and the use of a positive coping strategy. There were, however, some other interesting results from this data. For example, there was a significant negative correlation ( $\mathrm{r}=-$ $.204, \mathrm{p}<.05$ ) between years of service as a firefighter and the use of "emotional support" as a coping mechanism. This suggests that younger firefighters are more likely to rely on emotional support than their more experienced colleagues. Further there was a significant positive correlation $(r=.301, p<.05)$ between years of service as a firefighter and the use of "self-blame" (a negative coping strategy). There was also a significant correlation ( $\mathrm{r}=.200$, $\mathrm{p}<.05$ ) between years of service and the use of "behavioral disengagement" (a negative coping strategy). 
Table 1. Mean and rank of PTSD symptoms (PCL-CV) (Note: The five highest ranked symptoms are bolded)

\begin{tabular}{|l|c|c|}
\hline \multicolumn{1}{|c|}{ PTSD Symptoms } & Mean Score & Rank of Symptom \\
\hline Disturbing Memories & $\mathbf{1 . 6 7}$ & $\mathbf{5}$ \\
\hline Disturbing Dreams & 1.37 & 12 \\
\hline Reliving Stressful Experience & 1.32 & 14 \\
\hline Feeling Very Upset & 1.62 & 6 \\
\hline Physical Reactions & 1.41 & 11 \\
\hline Avoid Thinking/Talking About Stressful Experience & $\mathbf{1 . 7 4}$ & $\mathbf{4}$ \\
\hline Avoiding Activities That Remind You of the Stressful Experience & 1.49 & 8 \\
\hline Trouble Remembering & 1.34 & 13 \\
\hline Loss of Interest in Activities & 1.47 & 9 \\
\hline Feeling Distant From Others & 1.47 & 9 \\
\hline Feeling Emotionally Numb & 1.42 & 10 \\
\hline Feel Future Will Be Cut Short & $\mathbf{1 . 6 7}$ & $\mathbf{5}$ \\
\hline Trouble Sleeping & $\mathbf{2 . 0 1}$ & $\mathbf{1}$ \\
\hline Feel Irritable/Angry Outbursts & $\mathbf{1 . 9 6}$ & $\mathbf{2}$ \\
\hline Difficulty Concentrating & $\mathbf{1 . 7 9}$ & $\mathbf{3}$ \\
\hline Being “Super-Alert” & $\mathbf{1 . 9 6}$ & 7 \\
\hline Feeling Jumpy & 1.56 & $\mathbf{2}$ \\
\hline
\end{tabular}

Of the four coping strategies that were predicted to be the most frequently used, the three positive strategies were found to be among the top five, but substance use was ranked tenth. Table 2 shows the mean value and relative rank of each of the coping strategies:

Table 2. Mean and rank of coping responses from the Brief Cope Scale. The top 5 ranked coping strategies are printed in bold type. Note: mean refers to the arithmetic average of the two questions that are asked about each of the coping responses across all subjects.

\begin{tabular}{|l|c|c|}
\hline \multicolumn{1}{|c|}{ Coping Response } & Mean & Rank \\
\hline Self-distraction & $\mathbf{1 . 5 4}$ & $\mathbf{3}$ \\
\hline Active Coping & 1.37 & 13 \\
\hline Denial & 1.18 & 10 \\
\hline Substance Use & 1.34 & 11 \\
\hline Use of Emotional Support & 1.31 & 12 \\
\hline Use of Instrumental Support & 1.24 & 14 \\
\hline Behavioral Disengagement & 1.15 & 6 \\
\hline Venting & 1.49 & $\mathbf{5}$ \\
\hline Positive Reframing & $\mathbf{1 . 4 9}$ & $\mathbf{7}$ \\
\hline Planning & 1.43 & $\mathbf{2}$ \\
\hline Humor & $\mathbf{1 . 5 6}$ & $\mathbf{1}$ \\
\hline Acceptance & $\mathbf{2 . 0 0}$ & $\mathbf{4}$ \\
\hline Religion & $\mathbf{1 . 5 0}$ & 9 \\
\hline Self-Blame & 1.37 & \\
\hline
\end{tabular}

\section{DISCUSSION}

As predicted, there was a significant positive correlation between years of service as a firefighter and selfreported PTSD symptoms. This finding is important but can be interpreted in several different ways. For example, are older people less able to cope with stress than younger ones, and does this lead to more frequent diagnoses of PTSD? Second, is this a cohort effect - that is, might it be that this particular cohort of individuals be unusually susceptible to trauma and stress, or conversely, are firefighters in a younger cohort better at coping with stress? So, it might be the age, or it might be just the particular groups of people that lead to differences in PTSD symptoms. Further, this might imply a cumulative impact of stress over the years, but this is difficult to tell in this study because the subjects were asked to think about stressful events that had occurred in the past year. Thus, we do know that 
firefighters with more years on the job are more likely to report more PTSD symptoms than those with fewer years, although the precise reasons are not clear from the present research.

One thing that must also be mentioned is that the PTSD measure is based on self-report rather than a diagnosis by a mental health professional. While this might seem to be an issue, it should be remembered that most of the diagnostic criteria for PTSD are based on self-report symptoms. As reported earlier, $6.6 \%$ of firefighters in this sample scored high enough on the PCL-CV survey to suggest the diagnosis of PTSD, while earlier in this paper it was noted that the lifetime incidence for the general population for PTSD is $8 \%$ and the lifetime incidence for firefighters is $22.2 \%$. Since the mean years of service in this population was about 15 and the mean age was about 40 , most of the subjects are quite a ways away from the end of their lives, which means that the $6.6 \%$ incidence rate is not necessarily low. Further, there may have been some under-reporting of symptoms even though it was a confidential survey, and since it was done at work there may have been some reluctance to fully selfdisclose. It is also possible that some of the subjects may not have been very good reporters - that is, they may not have been totally aware of their symptoms.

Of the symptoms that were most frequently mentioned the results were not surprising. As noted in Table 1, "Trouble Sleeping" was the most frequently endorsed symptom followed by "Feeling Irritable/Angry" and "Being Super-Alert" which were tied for second. Ranked third was "Difficulty Concentrating" and fourth was "Avoid Thinking/Talking. Finally, "Disturbing Memories" and "Feeling the Future Will Be Cut Short" were tied for fifth. Interestingly, the first three symptoms mentioned were "Trouble Sleeping," "Feeling Irritable/Angry," and "Being Super-Alert." These symptoms suggest physical and emotional reactions while the last three seem to involve more cognitive symptoms. Of course, there are cognitive and emotional aspects in all of these issues to some degree, but other work has suggested that men often respond to physical symptoms of their disorders before they recognize the emotional issues (Nydegger, 2008).

The Coping results were particularly interesting since the hypothesis that there would be a correlation between years of service and the use of positive coping mechanisms was not supported. In fact, there was a significant negative correlation between years of service the "the use of emotional support" as a positive coping strategy. This clearly suggests that firefighters with less experience are more likely to rely upon emotional support to help them cope than are firefighters with more years of experience. Further, the longer a firefighter is on the job the more likely he (since all of the subjects in this study were male) is to use "self blame" and "behavioral disengagement" as coping mechanisms. These findings are of concern because they suggest that the least experienced firefighters will be more likely to use "emotional support" (a positive coping mechanism), while the most experienced firefighters are more likely to use "self blame" and "behavioral disengagement" (both negative coping mechanisms) to deal with stress and trauma.

A more encouraging finding was that, of the five more frequently mentioned coping strategies, four were positive: acceptance, humor, religion, and positive reframing. Self-distraction was the only negative coping mechanism that was in the top five. The reason that self-distraction is classed as a negative coping strategy is that it involves changing one's focus from what is bothering them to something else. In the short term this can be positive, but if it continues then the person is not doing anything to actually deal with the source of the problem and it will continue longer than it needs to and possibly become more serious. However, even among the negative coping strategies, "distraction" is not as seriously pathological as others, and particularly in the short term. It is somewhat encouraging that the subjects primarily identify positive coping mechanisms for dealing with stress/trauma, but it must be remembered that these are self-report inventories and these results depend upon the person being truthful in their responses, and also assumes that they are accurately reported how they cope when it may be that they simply do not realize when they are using some of the negative strategies. For example, it is easy to assume that one is more irritable because the people around them are just annoying rather than realizing that they are really the source of their own irritability. Or, if a person is actively denying that something bothers them they probably would not even be aware that they were doing this. Finally, even though the questionnaires were anonymous, the subjects may not have wanted to portray themselves or their profession in negative ways and minimized the negative responses. However, even with these limitations, the results indicate that firefighters appear to be aware of the importance of using more positive coping mechanisms even if they might not use them as often as they report. 
Although the findings from this study may generate more questions than answers, they certainly do point out the importance of further research in this area. However, one thing seems clear and that is that firefighters are at risk for experiencing stress and trauma, and that this risk often leads to the experience of PTSD symptoms. Whether or not stress has a cumulative impact, and we think it does, these results do suggest that the longer a person is a firefighter the more likely they are to experience PTSD symptoms. While this could be due to age or cohort effects, other research (e.g., Corneil, 1995; Del Ben, et al., 2006; Haslam \& Mallon, 2003) also concludes that there is a cumulative impact of stress over time with firefighters. The most conservative interpretation of all of these findings is that firefighting is a potentially stressful profession, and over the working life of a firefighter they are very likely to experience stress and trauma that will impact them in such a way as to result in PTSD symptoms. A positive note is that firefighters do seem to recognize the importance of more positive coping mechanisms although it is less clear as to whether or not they actually use them. However, this suggests that firefighters (as well as other public service emergency and military personnel) should be provided with more training and support for dealing with stress and trauma. A boring lecture and post-event debriefings are not enough to prevent problems resulting from the trauma that these workers experience. Of course, over-reacting is not helpful either, but having continuing, supportive and responsive programs that identify problems early and provide the resources the help these professionals deal with the realities of their work is good practice. It is also a very cost effective approach as well. Ask most fire and police departments how many Worker's Compensation benefits are paid for stress leaves, how much in the way of medical expense is generated because of stress problems, and how many disability retirements involve stress, and you might be surprised. You might also want to ask how much of their overtime budget is spent covering for people who cannot work because of stress-related problems. Clearly, dealing with stress and trauma among firefighters and other emergency service personnel is important from a human standpoint, but it is also important from and organizational and budgetary standpoint as well.

\section{BIOGRAPHY}

Rudy Nydegger, Ph.D., ABPP is a Professor of Management and Psychology at the School of Management in the Union Graduate College, and the Department of Psychology at Union College. In addition, he is Chief of the Division of Psychology at Ellis Hospital and is on the Executive Board of the National Register of Health Service Providers in Psychology. He is certified in Clinical Psychology by the American Board of Professional Psychology and is a Fellow in the American Academy of Clinical Psychology. He is Principal in a psychological and management consulting firm, and is actively involved in a number of professional organizations. His teaching, research, and writing focus on areas in applied psychology and management.

Liesl Nydegger, BA graduated from Siena College with a degree in Psychology, and has completed her MPH in Public Health at Claremont Graduate University where she has also worked in the areas of Organizational Behavior and Evaluation. She is a Ph.D. Candidate in Global Health in the School of Community and Global Health at Claremont Graduate University where her research focuses on the design, implementation, and evaluation of AIDS prevention programs. She has also done research in Organizational Behavior and Health Psychology. Currently she is the Membership Co-Chair of the American Public Health Association-Student Assembly.

Frank Basile, Jr. graduated from Union College in 2007 with a Bachelors of Science degree in Psychology and minor in Economics. At young age, Frank became very interested in becoming a firefighter. During his time at Union College, he chose to explore the relationship between firefighters and PTSD, as well as the coping methods of these individuals. Frank resides in New Hartford, NY where he is volunteer firefighter and also an EMT for a commercial ambulance service. Frank is currently employed by Excellus BlueCross BlueShield and is pursuing his Masters of Business Administration.

\section{REFERENCES}

1. American Psychiatric Association. (2000). Diagnostic and statistical manual of mental disorders. Washington, DC.

2. Bacharach, S. B., Bamberger, P.A., \& Doveh, E. (2008). Firefighters, critical incidents, and drinking to cope: The adequacy of unit-level performance resources as a source of vulnerability and protection. Journal of Applied Psychology, 93, 155-169. 
3. Barlow, D. H., \& Durand, V.M. (2005). Abnormal Psychology: An Integrative Approach. California: Wadsworth.

4. Beaton, R., Murphy, S., Johnson, C., Pike, K., \& Corneil. W. (1998). Exposure to duty-related incident stressor in urban firefighters and paramedics. Journal of Traumatic Stress, 11, 821-828.

5. Beaton, R., Murphy, S., Johnson, C., Pike, K., \& Corneil. W. (1998). Exposure to duty-related incident stressor in urban firefighters and paramedics. Journal of Traumatic Stress, 11, 821-828.

6. Beaton, R., Murphy, S., Johnson, C., Pike, K., \& Corneil. W. (1999). Coping responses and post-traumatic stress symptomatology in urban fire service personnel. Journal of Traumatic Stress, 12, 293-308.

7. Brown, J., Mulhern, G., \& Joseph, S. (2002). Incident-related stressors, locus of control, coping, and psychological distress among firefighters. Journal of Traumatic Stress, 15, 161-168.

8. Carver, C., Scheier, M., \& Weintraub, J. (1989). Assessing coping strategies: A theoretically based approach. Journal of Personality and Social Psychology, 56, 267-283.

9. Corneil, W. (1995). Traumatic stress \& organizational strain in the fire service. Job Stress Interventions, 185-198.

10. Del Ben, K., Scotti, J., Chen, Y., \& Fortson, B. (2006). Prevalence of post-traumatic stress disorder symptoms in firefighters. Work \& Stress, 20, 31-48.

11. Harris, M. B., Balogla, M., \& Stacks, J.R. (2002). Mental health of trauma-exposed firefighters and critical incident stress debriefing. Journal of Loss and Trauma, 7, 233-238.

12. Haslam, C., \& Mallon, K. (2003). A preliminary investigation of post-traumatic stress symptoms among firefighters. Work \& Stress, 17, 277-285.

13. Heinrichs, M., Wagner, D., Schoch, W., Soravia, L.M., Hellhammer, D.H., \& Ehlert, U. (2005). Predicting post-traumatic stress symptoms from pretraumatic risk factors: a 2-year prospective follow-up study in firefighters. American Journal of Psychiatry, 162, 2276-2286.

14. Jeannette, J. M., \& Scoboria, A. (2008). Firefighter preferences regarding post-incident intervention. Work \& Stress, 22, 314-326.

15. Kessler, R.C., Sonnega, A., Bromet, E., Hughes, M., \& Nelson, C. (1995). Post-traumatic stress disorder in the National Comorbidity Survey. Archives of General Psychiatry, 12, 1048-1060.

16. Landen, S. M., \& Wang, C.C. (2010). Adult attachment, work cohesion, coping, and psychological wellbeing of firefighters. Counseling Psychology Quarterly, 23(143-162).

17. New York State Public Employees Federation. (2006). Occupational stress fact sheet.

18. Nydegger, R.V. (2008). Understanding and Treating Depression: Ways to Find Hope and Help. New York: Praeger.

19. Oginska-Bulik, N. (2005). The role of personal and social resources in preventing adverse Health outcomes in employees of uniformed professions. International Journal of Occupational Medicine and Environmental Health, 18, 233-240.

20. van Wormer, K., \& Boes, M. (1997). Humor in the emergency room: A social work perspective. Health and Social Work, 22, 87-92. 


\section{NOTES}

